\title{
Understanding the Motives for Joining Ethnic Online Communities: A Study of Turks in Norway
}

\section{Etnik Çevrimiçi Topluluklara Katılım Motivasyonlarını Anlamak: Norveç’te Yaşayan Türkiyeli Göçmenlere Yönelik Bir Çalışma}

\author{
Naim Çınar, Anadolu University, Turkey, naimcinar@anadolu.edu.tr \\ Abstract: This study intends to explore why ethnic online community members are willing to be a part of their community. Arnold and Schenieder \\ (2007)'s model of motivation for joining ethnic online communities was tested within the context of Turkish immigrants in Norway. Besides, this article \\ gives suggestions on ways of engaging with immigrants through social media.
}

Keywords: Ethnic Online Community, Integration, Motivation, Social Media

Öz: Bu araştırmanın amacı etnik çevrimiçi topluluk üyelerinin topluluğa üye olma motivasyonlarını ortaya koymaktır. Arnold ve Schenieder (2007) 'in etnik çevrimiçi topluluklara üye olma motivasyonlarına yönelik geliştirdiği model Norveç’te yaş̧ayan Türk göçmenler bağlaminda test edilmişstir. Bununla birlikte, gö̧̧menlerin entegrasyonu konusunda sosyal medyanın olası katkılarına yönelik önerilerde bulunulmuştur.

Anahtar Sözcükler: Etnik Çevrimiçi Topluluk, Entegrasyon, Motivasyon, Sosyal Medya

\section{Brief Summary}

Initially the Web was used as an information repository in which people could access information resources according to their needs. Today this one-way type of the Web has been transformed to a co-created, interactive, internet-based platform that includes various applications such as wikis, mashups, blogs, podcasts, RSS and social networks. New kinds of communicative practices and communities have sprung up depending on the developments in internet based information and communication technologies. Millions of internet users from all over the world meet online to chat, to meet with new people, to discuss with others, to give or ask for information. These online social gatherings are known by a variety of names including 'online community'. Rheingold (1994), describes online communities as cultural aggregations that emerge when enough people bump into each other often in cyberspace. The future of online communities is very promising: technological infrastructure supporting online communities is developing rapidly and it is expected that the deployment of online communities will become more and more comprehensive and widespread (Blossom, 2005).

\section{Online Communities}

In order to get a sense of perspective about online communities we need to think about what community means today. Thinking about what makes a community and what its members get from belonging to that community has been the main concerns of the study of communities.

A multidisciplinary group of researchers held a workshop at the Computer Supported Cooperative Work conference in which they identified the core attributes of communities (Whittaker et al., 1997):

"(i) members have a shared goal, interest, need, or activity that provides the primary reason for belonging to the community, (ii) members engage in repeated active participation and there are often intense interactions, strong emotional ties and shared activities occurring between participants, (iii) members have access to shared resources and there are policies for determining access to those resources, (iv) reciprocity of information, support and services between members, and (v) shared context (social conventions, language, protocols)."

Before moving to the next step in defining online communities we should mention one particular form of community, which offers important insights for our discussion. Benedict Anderson's conception of imagined communities means that the work of making a nation as a community depends on the use of symbolic resources and devices: because we can never know or interact with all those others with whom we share national identification, we need 'things' to coalesce a shared sense of identity around a flag, a national anthem, a set of customs and rituals (sometimes referred to as 'invented traditions'). These kinds of communities only exist because their members believe in them, and maintain them through shared cultural practices (Bell, 2001). This definition made it possible to think of communities in a structural way, going beyond a historical and geographic characterization (Mitra, 1997).

Many researchers have defined and redefined the notion of community since internet has started to have a significant effect on the way we form communities we live in and interact with. Over the past two decades a large number of studies 
have attempted to understand how internet and communities intertwine with each other. There are still discussions of opposing views about the online forums being a community or not? Consequently, as Mitra (1997) said: "it is relatively difficult (and perhaps fruitless) to arrive at a definitive description of community because that itself is a provisional construct changing in meaning as new technologies of communication evolve".

The internet has been considered an ideal medium for building and maintaining a community. Many people from all over the world meet online around wide variety of topics. These online social gatherings on internet are known as online communities. Online communities and social media in general, characterized by user generated content, provide new opportunities for contact with various communities (Dekker et al., 2015). Howard Rheingold, one of the pioneers of online community research describes it thus: "In cyberspace, we chat, argue, engage in intellectual intercourse, perform acts of commerce, exchange knowledge, share emotional support, make plans, brainstorm, gossip, flirt, create a little high art and a lot of idle talk. We do everything people do when they get together, but we do it with words on computer screens, leaving our bodies behind. Millions of us have already built communities where our identities commingle and interact electronically, independent of local time or location" (Rheingold, 1999). Following that he concludes that online community formation occurs when enough people bump into each other often in cyberspace.

\section{Ethnic Online Communities}

The internet is a unique environment where all kinds of groups and ideas are represented. It has great advantages for intergroup contact over traditional face-to-face communication. The social networking websites on the internet are ideal places for interaction and user generated content. They provide brand new opportunities for getting in touch with all sorts of communities (Boyd and Ellison, 2007). As Kahin and Keller (1995) stated, the human need for affiliation is at least as strong as the need for information. Therefore, people are usually participate to online groups that share their interests and concerns (Preece and Krichmar, 2003).

Online communities are very diverse in their formation, evolution, content and goals. It is possible to find online communities about all kinds of interests. Thousands of networks are devoted to bringing together like-minded souls (Norris, 2002). Online religious communities are ideal places for communicating religious beliefs and practices. Communities of practice create new products, processes, and services online. Social movements are creating online communities for coordinating successfully on international level. The darker side of the internet is also represented by fascist or extreme religious groups. These groups have formed online communities with the purpose of recruiting members and supporting their organizations. Cyberspace is a pluralistic, multi-tasking and distributed environment made up of very different sub-contexts of communication. Therefore online communities are to be understood, their singularity and uniqueness must be taken into account (Diamandaki, 2003).

This study focuses on "ethnic online communities". Ultimately, the online world is based on people interacting and establishing relationships. There must be some shared interest and background. What's more powerful than race and ethnicity? (McLaine, 2003)

According to literature, immigrants have a natural inclination to communicate with their ethnic peers, and ethnic communication activities are helpful in their cultural adaptation process (Ke and Chang, 2009) and media serves as a very powerful tool for these communication activities. Media has a crucial role in immigrants' lives in keeping with the diversity and dynamics of the ongoing adjustment to the host culture and preservation of their original cultural identity (Khvorostianov et al., 2011) Highlighting the relationship between diaspora and media, Dayan (1999) describes diaspora as the migration and displacement of groups in their dislocation from the homeland, which maintain continuous links to the country of origin. Communities in diaspora, increasingly form micro-public spheres, interacting with macro-public sphere and providing spaces for minority groups to produce mediated conceptions of the self and the community. (De Leeuw and Rydin, 2007).

The rise of the Internet has dramatically altered people's communication activities. The internet offers the means for online gatherings, so that it gives great opportunities for social interaction among individuals-particularly those who otherwise would not have had the opportunity, nor perhaps the inclination, to meet. People are increasingly turning to the internet as a quick and easy way to maintain contact with others (McKenna and Bargh, 2000). Theories in cultural adaptation have pointed out that learning about the host culture through communication is the key issue in cultural adaptation. Therefore, the Internet has potential to influence the cultural adaptation patterns among immigrants and sojourners (Beom, 2003). New virtual environments have the potential to effect the integrative capacities of the users, such as the establishment of social relations across ethnic borders and the accessing of information that could lead to increased inter-ethnic understanding and in the case of immigrants this new media environment would provide ample opportunities to engage in intra and inter-ethnic contact (Franz and Götzenbrucker, 2012). The Internet - especially online communities - is an ideal resource for immigrants' cultural learning and adaptation apart from face-to-face interactions and traditional media. According to McKenna and Bargh (1998), minority group members use the internet to find orientation, social acceptance and contact with other like minded people. Internet and therefore online communities provide with new ways to relate to their ethnic communities, both to people in their home country and to people in the host country (Elias and Lemish, 2009). Some scholars, use the term "digital diasporas" to explain the interaction of immigrants in online environments. Digital diaspora is defined as the use of cyberspace by diasporic groups, including immigrants or descendants of an immigrant group that uses IT connectivity to participate in virtual networks of contacts for a variety of purposes, for the most part, may concern either the home culture, the host culture, or both (Laguerre, 
2010). It is through this conceptualization that ethnic online communities' have the potential to be a place for recreation of identities, opportunity sharing, spreading cultures, and influencing both the home culture and the host culture (Lee, 2012)

Immigrants are more likely to seek help and share feelings with their fellow citizens in foreign countries. Ethnic online communities are ideal places to accommodate this inclination because they are inexpensive, easy to access and interactive. Online communities provides opportunities for immigrants to connect with each other, breaking the geographical restrictions. They offer a space in which immigrant communities, mostly lacking economic or political power, are able to develop efficient channels for spreading information that is vital to their survival in the new society (Khvorostianov et al., 2011). The immigrants can now transcend the barriers of space and time to participate in conversations to discover a new sense of fellowship (Ebihara, 1996).

To sum up, a growing body of literature (Arnold and Schneider, 2007; Beom, 2003; Dekker et al., 2015; De Leeuw and Rydin, 2007; Diamandaki, 2003; Elias and Lemis, 2009; Franz and Götzenbrucker, 2012; Ke and Chang, 2009; Khvorostianov et al. 2011; Lee, 2012; McKenna et al., 2000; McLaine, 2003; Mitra, 1997) have focused on how immigrants utilize online communities to communicate, interact, maintain their identity. These studies on ethnic communities online have focused on the implications of social media for inter or/and intra-ethnic contact. On the one hand, these online gatherings may foster inter-ethnic contact by providing new social network infrastructures. Thus, they would facilitate integration of ethnic minorities in their host societies. On the other hand, they may strengthen intra-ethnic contact and impede inter-ethnic contact by connecting ethnic minorities to their countries of origin within so called 'transnational communities'. Social media has indeed a relevant sphere for inter-ethnic contact, therefore it does not only support intra-ethnic bonding but both inter and intra-ethnic contact.

\section{The Case of Turks in Norway}

According to International Organization for Migration the total number of international migrants has increased over the last years from an estimated 150 million in 2000 to 232 million persons ( $3.2 \%$ of the world's population) by the end of $2013^{1}$. In 2010, the population in Norway comprised 5,156,451 people and the proportion constituted by immigrants and those born in Norway by immigrant parents totalled 760,000 (14.9\%). In 2014, there were more than 16,000 Turkish immigrants and descendants, corresponding to about $2.1 \%$ of the total group of foreigners in Norway ${ }^{2}$.

Migration can be viewed as a journey from one culture to another. Culture is defined in many ways. According to Adler and Gundersen (1991), culture is what is shared by all members of some social cluster, in which older members of the society tend to pass on to the younger members and finally it is something that shapes behaviour or structures one's paradigm. According to Hofstede (1980) culture is the collective programming of the mind, which distinguishes one human group from another.

Since culture distinguishes one group of people from the cohort, it is natural that the result of migration creates diversity. Cultural diversity can be seen as the outcome of migration. Cultural diversity can exist both within and among cultures (Adler and Gundersen, 1991). Since every culture has its own peculiar aspect, each immigrant creates cultural diversity in the host country. Cultural diversity carries both negative and positive aspects. Diversity means multiple perspectives, interpretations, which increases society's overall potential of creativity, flexibility and problem-solving skills. But on the other hand it means a gap between the immigrant and the host country. This gap creates ambiguity, complexity and confusion, which leads to misunderstanding and a diminished level of tolerance (Adler and Gundersen, 1991).

Host country nationals answers to migration and the responses they receive from the immigrants can be labelled as acculturation attitudes (Berry, 1980). The dominant acculturation attitudes determine whether a society favours from the advantages of cultural diversity or not. Acculturation attitudes were introduced as a four-fielder approach by John W. Berry in 1980. Interaction between the attitudes of both the hosts and the immigrants composes the four options in terms of acculturation. The first dimension is whether or not an individual values maintaining his/her cultural characteristics. The second dimension is whether or not maintaining relationships with the host society is considered to be of value. The answers to these dimensions can be "yes" or "no," thus the four-fielder is composed. According to the model if the response to the first dimension is "no" and to the second one is "yes," "assimilation" occurs. In this option, acculturating individual does not wish to maintain his/her cultural characteristics but seeks relations with the groups in the larger society. On the other side, separation occurs when there is a strong connection with one's own culture and identity and there is low level of intention to interact with groups in the larger society. Integration occurs when there is an interest in interacting with others, while conserving the cultural identity. Last section is marginalization. In this case, the individual neither intends to interact with the society nor maintains his/her cultural values. Among those four acculturation attitudes, integration was found to predict synergy and more fruitful outcomes. Successful integration ought to provide possibility to get the best of the both worlds.

Integration is easier said than done. Eriksen (2001) describes the complexity of the situation in Norway as follows; "on the one hand Norwegians have told them [immigrants] since childhood that they are different, while they in fact know no other homeland than Norway. On the other hand they often feel pressured by their parent generation to remain faithful to the traditional values and not become 'too Norwegian."

\footnotetext{
${ }^{1}$ http://www.unfpa.org/migration (Accessed on November, 2014)

${ }^{2}$ https://www.ssb.no/en/befolkning (Accessed on November, 2014)
} 
Another version of the same situation is also valid in Turkey. The Turkish term "Almancı" which literally means "German-like" is a concept used in Turkey in order to label the Turkish immigrants living in Europe. Immigrants are perceived in Turkey as "German-like" and in Europe they are called immigrants. Answers to the question "who am I?" becomes obscure as the same individual is sometimes called immigrant, sometimes "Germanized," sometimes guestworker and some other times Norwegian.

The answer to the question "who am I?" is constructing a person's identity. A person's identity is created by her/his interactions with social environment (Czarniawska-Joerges, 1997). Since identity is socially constructed, the identity construction process is apt to vary according to the environment in which the immigrant interacts (Kärreman and Alvesson, 2001).

Since its advent the Internet has become a popular social environment among people as well as immigrants. The rise of the Internet has altered immigrants' communication activities. Interactions among immigrants that take place within the online environments have potential to influence the integration process of immigrants. In the case of Turkish immigrants, in recent years many ethnic online communities have been established in Norway. Here is the alphabetically ordered list of active ethnic online communities composed of Turkish immigrants in Norway:

Table 1: List of ethnic online communities composed of Turkish immigrants in Norway

\begin{tabular}{|l|l|}
\hline \multicolumn{1}{|c|}{ Community Name } & Online Location \\
\hline Norges Tyrkiske Ungdomsforening & Facebook Group \\
\hline Den Tyrkisk Islamske Union & www.nortib.org \\
\hline Tyrkiske Foreningers Hovedorganisasjon & Facebook Group \\
\hline TURKa - Rhythm Organization & Facebook Group \\
\hline Norveç'teki Türkler & Facebook Group \\
\hline
\end{tabular}

The selected ethnic online communities in this paper are based primarily on the author's personal netsurfing experience, and his own judgement of the kind of information provided by the online communities. This list included more ethnic online communities but some of them had to be removed because of reasons like discontinuation of the online community or lack of active members.

As it can be seen on Table-1 the active ethnic online communities are mostly created on Facebook. Facebook and other major social networking websites let their users create online communities easily. Another advantage of these big social networks is the number of active users they have. Millions of people from all over the world with different backgrounds and interests join these big networks. Therefore it is relatively easier to create and/or find and join an online community of interest on big social networks. Just plenty of online communities that have their own web sites are now integrating their web sites with the major social networks by letting users join the online community with their existing social network accounts or by starting new groups on these social networks.

There are several other web sites related to Turkish immigrants in Norway but they are not considered as online communities since they are typical examples of information based web sites with no member interaction. For instance, some of the organizations operated by and for the Turkish community have active web sites. These web sites include information related to the organization, news about the Turkish community in Norway, news from Turkey and Norway and, links to useful resources (e.g.: Turkish Embassy in Norway, job search engines in Norway, newspapers from both Turkey and Norway, travel agency websites, language translation services, web sites about Turkish history, culture and religion).

\section{Research Methodology and Findings}

The online participants' ethnic online community participation motives were analyzed using the scale developed by Arnold and Schneider (2007). In their study, four factors were identified. The strongest factor refers solely to having 'fun' on the web. The second strongest factor was found to be 'bond to Turkey'. The third factor combines issues pertaining to 'community building' and the fourth and the least important factor is made up of issues pertaining to "orientation" in Germany. Due to the fact that Arnold and Schneider (2007)'s scale was tested on Turkish immigrants in Germany, the same scale was used to measure the Turkish immigrants' motivations for joining an ethnic online community. The items were translated to Turkish by the author. Two instructors from the School of Foreign Languages at Anadolu University reviewed the translations.

Table-2 shows the factors and the 16 items used to measure these factors: 
Table 2: Motives for being member of an ethnic online community

\begin{tabular}{|c|c|}
\hline & Factors \\
\hline Meeting Turks & \multirow{3}{*}{ Fun } \\
\hline Fun & \\
\hline Meeting people like oneself & \\
\hline Improving Turkish language & \multirow{5}{*}{ Bond to Turkey } \\
\hline Preserve ethnic origin & \\
\hline Improving Turkish-Norwegian relations & \\
\hline Connecting to Turkey & \\
\hline Contact to Turkey & \\
\hline Be taken seriously & \multirow{6}{*}{ Community building } \\
\hline Community with like-minded & \\
\hline Gaining new topics of conversation & \\
\hline Learn about trends & \\
\hline Be where the party is & \\
\hline Meeting people who understand my problems & \\
\hline Improving Norwegian language proficiency & \multirow[t]{2}{*}{ Orientation } \\
\hline Orientation in Norwegian everyday life & \\
\hline
\end{tabular}

The online survey was created and published with the open source online survey tool kwiksurveys.com. The online survey form was embedded to a web page that was built to conduct the online research. An email that explains the aim of this research was sent to the administrators of the ethnic online communities. They were requested to send the survey link to the online community members and share it on the online community homepage. The online survey was available online for one month and 92 ethnic online community members ( 43 female and 49 male) responded. All the respondents were from the Facebook groups (see Table-1). All the survey data was analyzed through SPSS version 20.

Graphic-1 shows the order of importance of the factors for respondents regarding their motivation for joining the ethnic online community. The most important factor is "Fun". Most respondents strongly agree on joining the community for meeting people like one self and having fun. Fun was also found to be the most important factor in the original study of Arnold and Schneider (2007). Similarly, in Franz and Götzenbrucker (2012)'s study a similar term "entertainment" was found to be the most popular use of social networks among young Turkish immigrants in Austria. An interesting result of this study is the high importance of "community building" among members whereas this factor was less important than "bond to Turkey" in the original study. This result can be interpreted as an opportunity in respect of communicating with Turkish immigrants in Norway through social media. The respondents join these online communities not just for fun or to connect with their ethnic background but also for feeling a sense of togetherness, learning new things and helping each other to solve their problems. "Bond to Turkey" is the third important factor. By contrast with the original study ethnic online community is not necessarily seen to be a place for improving Turkish language. The last and the least important factor is 'Orientation' but it is also a promising motivation for being an ethnic online community member. It is interesting to see that the main language of conversation in "Norges Tyrkiske Ungdomsforening" and "TURKa - Rhythm 
Çınar, N. / Journal of Yasar University, 2016, 11/42, 67-76

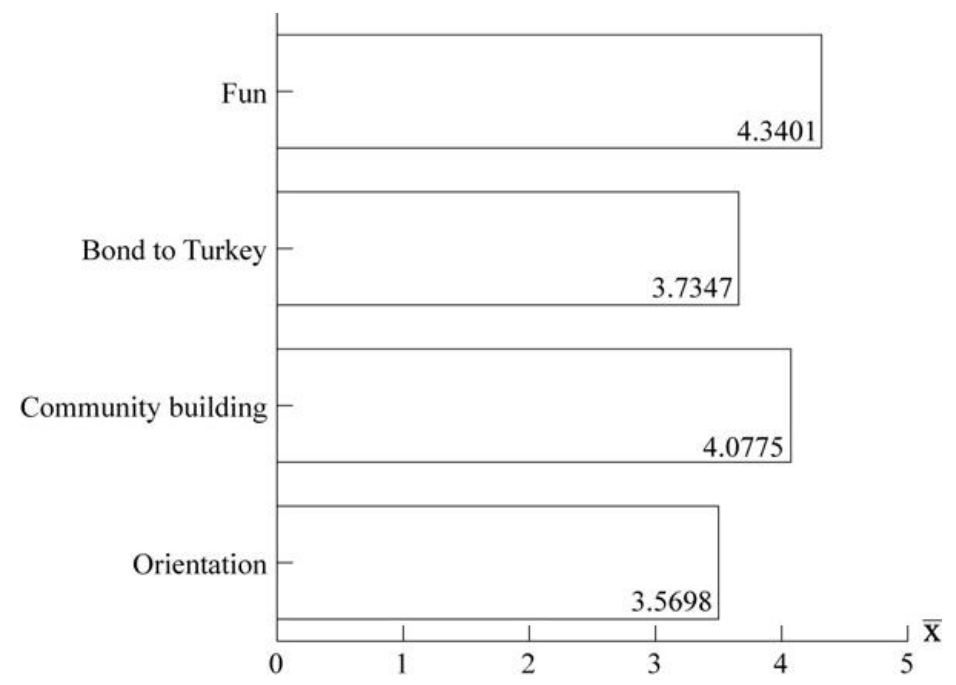

Graphic 1: The order of importance of the factors

Organization" Facebook groups is in Norwegian whereas Turkish is the only language of conversation in other three online communities. A comparison between these ethnic online communities would provide fruitful results to guide future studies.

An independent-samples T-Test was conducted to analyze the differences between genders. Test results shows that the difference between female and male respondents' motivations are non significant $(\mathrm{p}>0.05)$.

One-way ANOVA was used to test the differences between age groups. Table-3 shows that the difference between age groups is significant in "bond to Turkey" factor $(\mathrm{p}<0.05)$, whereas the differences between age groups are non significant in other three factors.

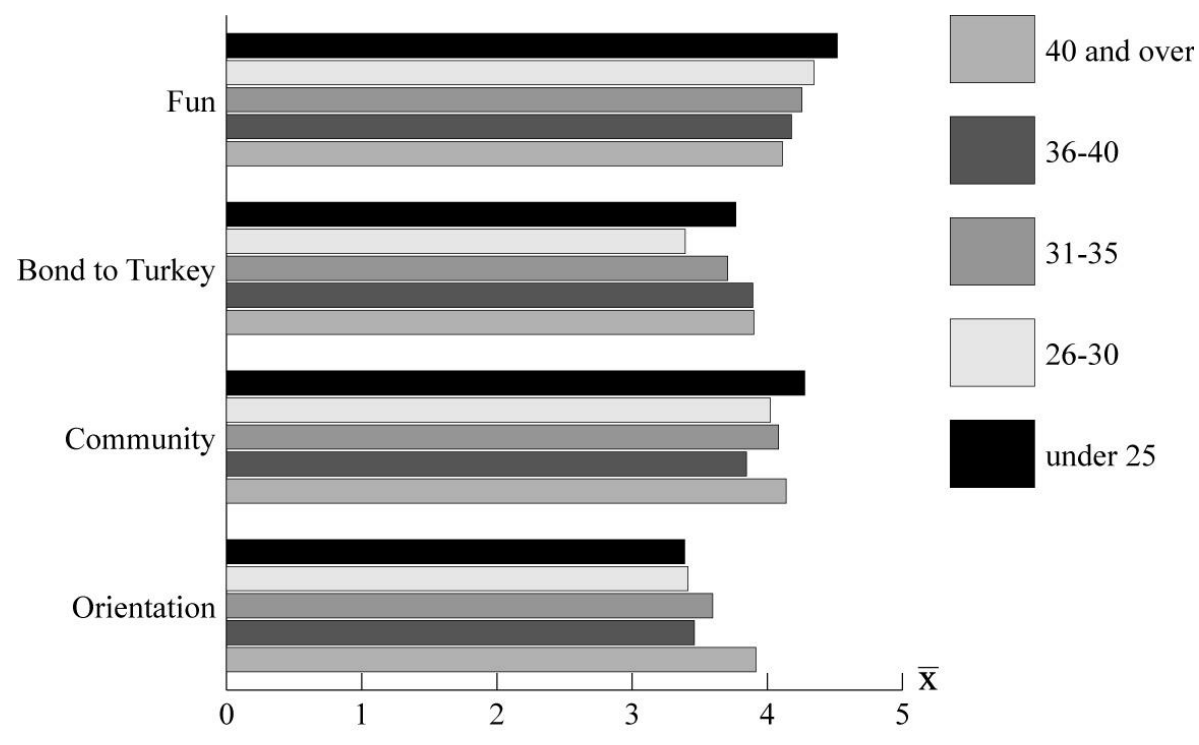

Graphic 2: The difference between age groups 
Table 3: Significance of the difference between age groups

\begin{tabular}{|c|c|c|c|c|c|c|}
\hline \multicolumn{7}{|c|}{ ANOVA } \\
\hline & & $\begin{array}{c}\text { Sum of } \\
\text { Squares }\end{array}$ & df & $\begin{array}{l}\text { Mean } \\
\text { Square }\end{array}$ & $\mathrm{F}$ & Sig. \\
\hline \multirow[t]{3}{*}{ Fun } & Between Groups & 1.349 & 4 & .337 & 1.495 & .211 \\
\hline & Within Groups & 19.621 & 87 & .226 & & \\
\hline & Total & 20.970 & 91 & & & \\
\hline \multirow[t]{3}{*}{ Bond to Turkey } & Between Groups & 3.377 & 4 & .844 & 3.057 & .021 \\
\hline & Within Groups & 24.026 & 87 & .276 & & \\
\hline & Total & 27.403 & 91 & & & \\
\hline \multirow[t]{3}{*}{ Community } & Between Groups & 1.525 & 4 & .381 & 2.439 & .053 \\
\hline & Within Groups & 13.603 & 87 & .156 & & \\
\hline & Total & 15.128 & 91 & & & \\
\hline \multirow[t]{3}{*}{ Orientation } & Between Groups & 1.739 & 4 & .435 & .784 & .539 \\
\hline & Within Groups & 48.261 & 87 & .555 & & \\
\hline & Total & 50.000 & 91 & & & \\
\hline
\end{tabular}

Following one-way analysis of variance (ANOVA), Fisher's Least Significant Difference (LSD) was used to compare the mean of one age group with mean of another. Table-4 shows that the respondents aged 26-30 years give less importance to "bond to Turkey" factor comparing to other age groups.

Table 4: Significance of the difference between age groups at 'Bond to Turkey' factor

\begin{tabular}{|c|c|c|c|c|}
\hline \multicolumn{5}{|c|}{ Multiple Comparisons } \\
\hline Dependent & ariable & (I) Age of participant & (J) Age of participant & Mean Difference (I-J) \\
\hline \multirow{4}{*}{$\begin{array}{l}\text { Bond to } \\
\text { Turkey }\end{array}$} & \multirow{4}{*}{ LSD } & \multirow{4}{*}{$26-30$} & under 25 & $-.37356^{*}$ \\
\hline & & & $31-35$ & $-.31459^{*}$ \\
\hline & & & $36-40$ & $-.49920^{*}$ \\
\hline & & & 41 and over & $-.50690^{*}$ \\
\hline The & $f f$ & is rimuificant at th & 05 level. & \\
\hline
\end{tabular}

\section{Conclusion}

In this study, the ethnic online community participation motives of community members were examined by looking at four factors. The results provide an understanding about the reason why community members join the ethnic online communities. In this case of ethnic online community members consisting of Turkish immigrants living in Norway, "fun", "community building", "bond to Turkey" and "orientation" are all observed to be important motivations for participating the ethnic online community. These findings show that, ethnic online communities are indeed relevant spheres for both inter and intra ethnic contact. Likewise the findings from previous studies "fun" is the most predominant one among these four motivations which means user join these communities mostly for meeting with like minded people, creating new relations and having fun.

An ethnic online community is an ideal place to link together immigrants and it provides great opportunities for their communication activities, cultural learning and adaptation process. Ethnic online communities have the potential to link together geographically isolated immigrants and provide them information resources that would help them to survive and succeed in Norway.

All of the ethnic online communities we have examined in this paper somehow provide information related to Turkish culture. It can be about a Turkish musician, the current political agenda in Turkey, a discussion about religion, the problems of Turkish immigrants in Norway, or a party organization of a group of Turkish immigrants. The ethnic online communities should be seen as important information resources that provide deeper understanding about the immigrants and a promising environment to foster integration. 
As it was mentioned before, learning about the host culture through communication is the key issues in cultural adaptation and government departments have the opportunity to increase their communication with various ethnic communities through social media channels. But in what ways and to what extent the governments should engage with them? The most important criteria is 'trust' when it comes to engaging them through internet. Building trust should be the first and foremost step for participating and joining the discussions in ethnic online communities. Because they will be aware of the fact that there is an outside organization within the community. The governments must take strategic steps in order to develop a communication based on trust.

A good example is Canadian immigration and settlement online community called LoonLounge.com ${ }^{3}$. It was created to improve the Canadian immigration process. According to LoonLounge.com its purpose is to empower Canadian residents, immigrants, and potential immigrants with the knowledge to build a stronger Canada together. The online community aims to help immigrants concerning various issues related to their integration in Canada. Its membership is made up of current Canadian residents, soon to be Canadian immigrants and many other people from all over the world. The online community provides a place for its members where they can meet with other people and learn about their immigration experience, ask questions and give advices to each other, search for job opportunities. It is also a place for education. Like many other online communities Loonlounge.com provides expert advices and suggestions, other kind of educational services and links to useful resources. Educational content appears to be the key element of ethnic online communities in consideration of the online communities we have examined in this paper and the participation motives of ethnic online community members.

Norway has a comprehensive and a well-established refugee resettlement program and has a reputation of showing high degree of tolerance to immigrants. The results of this study may help to find news ways for interaction between immigrants and the host culture (Norway) in an online environment. The Internet offers opportunities to communicate with immigrants through online communities and help them to integrate to the host culture.

This study has some limitations that need to be taken into account. We initially intended to enrich the quantitative data by supporting it with in depth interviews with ethnic online community members. Even though internet offers many opportunities to conduct online in depth interviews and focus groups, the geographic distance to potential respondents and the time limit of the researcher made it hard to reach and convince them to conduct the on line in depth interviews.

A number of avenues for future research arise from this study. It would be worthwhile to conduct a large scale study of online media consumption of ethic minority groups in Norway which might provide fruitful resources and directions for a better understanding of cyberspace' role in the process of integration of immigrants in Norway and the resocialization process in the cyberculture.

Another interesting study could be an extensive analysis of ethnic online communities of various ethnic groups through digital ethnography. It would provide rich cultural insights and contextual information which will lead the researcher to propose a theory driven design of a successful ethnic online community. The results of this study can be used as a starting point for future studies aimed at investigating the ethnic online communities.

\footnotetext{
${ }^{3}$ http://www.loonlounge.com
} 


\section{REFERENCES}

Adler, Nancy and Allison Gundersen. 1991. International Dimensions of Organizational Behaviour, PWS-KENT Publishing Company, Boston, Massachusetts.

Arnold, Anne-Katrin and Beate Schneider. 2007. "Communicating Seperation?: Ethnic Media and Ethnic Journalists as Institutions of Integration in Germany" Journalism, 8: 115-136.

Beom, Khisu. 2003. "The influence of Internet use and intercultural communication apprehension on socio-cultural adaptation" Paper presented at the annual meeting of the International Communication Association, Marriott Hotel, San Diego, CA.

Berry, John W. 1980. 'Acculturation as Varieties Adaptation' in A. Padilla (Eds), Acculturation: Theory, Models and Some New Findings (pp. 9-25). Westview Press: Boulder.

Blossom, John. 2005. "User-Generated Media and Its Future Next to Traditional Publishing", available at http://www.masternewmedia.org/news/2005/12/20/usergenerated media and its future.htm (Accessed on November 2014).

Boyd, Danah B. and Nicole B. Ellison. 2007. "Social Networking Sites: Definition, History, and Scholarship" Journal of Computer-Mediated Communication, 13(1): 210-230.

Czarniawska-Joerges, Barbara. 1997. "Narratives of Individual and Organizational Identities" Communication Yearbook, 17: 193-221.

Dekker, Rianne, Warda Belabas and Peter Scholten. 2015. "Interethnic Contact Online: Contextualising the Implications of Social Media Use by Second-Generation Migrant Youth" Journal of Intercultural Studies, 36(4):450-467.

De Leeuw, Sonja and Ingegerd Rydin. 2007. "Migrant Children's Digital Stories Identify Formation and SelfRepresentation Through Media Production" European Journal of Cultural Studies, 10(4), 447-464.

Diamandaki, Katerina. 2003. "Virtual Ethnicity and Digital Diasporas: Identity Construction in Cyberspace" Global Media Journal, 22(2).

Ebihara Wataru. 1996. "The Internet Guide for Asian American Cybernauts", available at http://janet.org/ ebihara/wataru aacyber.html (Accessed on September 2014).

Elias, Nelly and Dafna Lemish. 2009. "Spinning the web of Identity: The Roles of the Internet in the Lives of Immigrant Adolescents" New Media\&Society, 11(4): 533-551.

Eriksen, Thomas Hylland. 2001. Ethnic identity, national identity and intergroup conflict: The significance of personal experiences. In Ashmore, Jussim, Wilder (ed.), Social identity, Intergroup Conflict, and Conflict Reduction (p. 42-70). Oxford University Press: Oxford

Franz, Barbara and Gerit Götzenbrucker. 2012. "The Second Generation and the Use of the Internet: Communication and Friendship Structures of Young Turks in Vienna, Austria" International Journal of Humanities and Social Science, 2(5): 38-49.

Hofstede, Geert. 1980. Culture's Consequences, Sage Publication, Beverly Hills, California.

Kahin, Brian and James Keller. (Eds.) 1995. Public Access to the Internet. MA: The MIT Press.

Kärreman, Dan and Mats Alvesson. 2001. "Making newsmakers: Conversational identity at work" Organization Studies, 22(59): 59-89.

Ke, Nan. and Chang, Hui-Ching. 2009. "Cultural Adaptation and Ethnic Online Communities: A Study of Chinese Sojourners in the U. S." Paper presented at the annual meeting of the International Communication Association, Marriott, Chicago, IL.

Khvorostianov, Natalia, Nelly Elias and Galit Nimrod. 2011. "“Without it I am Nothing': The Internet in the Lives of Older Immigrants", New Media and Society, 14(4): 583-599.

Laguerre, Michel S. 2010. 'Digital Diaspora: Definition and Models' in A. Alonso and P. J. Olarzabal (Eds), Diasporas in the New Media Age (pp. 49-64). University of Nevada Press: Las Vegas.

Lee, Eunkyung. "Digital Diaspora on the Web: The Formation and Role of an Online Community of Female Korean im/migrants in the US." Doctoral Dissertation, Rutgers University, 2012.

McKenna, Katelyn. and Bargh John. 1998. "Coming Out in the Age of Internet: Identity Demarginalization through Virtual Group Participation”, Journal of Personality and Social Psychology, 75(3): 443-468.

McKenna, Katelyn. and Bargh John. 2000. "Plan 9 from Cyberspace: The Implications of the Internet for Personality and Social Psychology", Personality and Social Psychology Review, 4(1): 57-75.

McLaine, Steven. 2003. 'Ethnic online communities: Between Profit and Purpose' in McCaughey, Martha and Miachel Ayers (Eds), Cyberactivism: Online Activism in Theory and Practice (pp. 233-254). New York: Routledge.

Mitra, Ananda. 1997. Virtual Commonality: Looking for India on the Internet. In S. Jones (ed.), Virtual Culture: Identity and Communication in Cybersociety (pp. 55-79). Thousand Oaks: Sage Publications.

OECD. 2007. 'Participative Web and User-Created Content: Web 2.0, Wikis and Social Networking', available at http://www.oecd.org/sti/38393115.pdf (Accessed on November 2014).

Norris, Pippa. 2002. "The Bridging and Bonding Role of Online Communities" The International Journal of Press/Politics, 7(3): 3-13.

Preece, Jenny and Diane Maloney-Krichmar. 2003. 'Online Communities’ In J. Jacko and A. Sears, A. (Eds.) Handbook of Human-Computer Interaction, Lawrence Erlbaum Associates Inc. Publishers. Mahwah: NJ. 596-620. 
Rheingold, Howard. 1993. The Virtual Community. Homesteading on the Electronic Frontier. Reading, MA: AddisonWesley Publishing.

SSB Statistics Norway. 2014. 'Immigration and Immigrants', available at http://www.ssb.no/innvandring en/ (Accessed on November 2014).

Whittaker, Steve, Ellen Issacs and Vicki O'Day. 1997. "Widening the Net. Workshop Report on the Theory and Practice of Physical and Network Communities" SIGCHI Bulletin, 29(3): 27-30. 